\section{Changes in Pyruvic Acid Content and GPT Activity in Chilling-sensitive and Nonsensitive Crops}

\author{
Hironobu Tsuchida and Cheng Dan-Hong \\ Faculty of Agriculture, Kobe University, Rokkodai-cho, Nadaku, Kobe, \\ Japan
}

\author{
Kazuko Inoue \\ Consumer Economic Research Institute, 6-28, 1-cho, Nakatsu, \\ Ooyodo-ku, Osaka, Japan
}

\section{Nobuyuki Kozukue \\ Department of Home Economics, Kenmei Junior College, 68-Honmachi, Himeji City, Japan}

\section{Susumu Mizuno \\ Faculty of Agriculture, Kobe University, Rokkodai-cho, Nadaku, Kobe, Japan}

Additional index words. chilling injury, glutamate-pyruvate transaminase, cucumber, eggplant, carrots, Cucumis sativus, Daucus carota, Solanum melongena

Abstract. This study investigated the mechanism of alanine accumulation observed as a common factor in chilling-sensitive crops [cucumber (Cucumis sativus L.) and eggplant (Solanum melongena L.)] during cold storage. Pyruvic acid in-keto acids increased rapidly during the storage of these crops at $1 \mathrm{C}$. However, in sensitive crops at $20 \mathrm{C}$ or in a chilling-resistant crop [carrot (Daucus carota $\mathrm{L}$.)] at $1 \mathrm{C}$, the increase was not found. No significant changes in glutamate-pyruvate transaminase (GPT) activity closely related to the biosynthesis of alanine were found in chilling-sensitive or chilling-resistant crops during storage at 1,5 , or $20 \mathrm{C}$. We suggest that the accumulated alanine found in chilling-sensitive crops may be produced by GPT from accumulated pyruvic acid during cold storage.

Fruits and vegetables can roughly be divided into those that are sensitive to low temperatures, causing injuries during storage below $10 \mathrm{C}$, but above $0 \mathrm{C}$, and those that are resistant. Assuming certain factors in common with these two groups in metabolic mechanisms, a series of studies was carried out. We noted that in fruits and vegetables highly sensitive to and markedly injured by low temperatures, the accumulation of alanine is more noticeable (5).

To investigate the cause of alanine accumulation in-chilling-sensitive crops, we attempted to determine the content of pyruvic acid and the changes in glutamate-pyruvate transaminase (GPT) that are closely related to the biosynthesis of alanine in biological samples (11).

Mature cucumbers ('Hokyoku No. 2'average weight, $49.5 \mathrm{~g}$; length, $19.5 \mathrm{~cm}$; width of center, $2.4 \mathrm{~cm}$ ) and eggplants ('Senryo No. 2'-weight, 64.5 g; length, 9.7 $\mathrm{cm}$; width, 4.1. $\mathrm{cm}$ ) were used as chillingsensitive-crops, Chile carrots ('Hokoku No. 2'-weight, $49.5 \mathrm{~g}$; length, $36.8 \mathrm{~cm}$; width,

Received for publication 29 July 1988 . The cost of publishing this paper was defrayed in part by the payment of page charges. Under postal regulations, this paper therefore must be hereby marked advertisement solely to indicate this fact.
$5.3 \mathrm{~cm}$ ) were used as a chilling-resistant crop. All of the crops were purchased in 1985 from the eastern market of Kobe. After purchase, the crops were washed thoroughly and stored immediately at $1 \mathrm{C}(80 \%$ to $83 \% \mathrm{RH}), 5 \mathrm{C}$ ( $80 \%$ to $85 \% \mathrm{RH})$, or $20 \mathrm{C}(80 \%$ to $85 \% \mathrm{RH})$ in darkness until used.

Pyruvic acid was extracted by the method of Ishetwood and Cruickshank (3). For each sample, $10 \mathrm{~g}$ of the edible portion was placed bars indicate SE. into -80C methanol (mixture of solid $\mathrm{CO}_{2}$ and methanol); the acid was then extracted with $0.6 \mathrm{M} \mathrm{HPO}_{3}$ at $0 \mathrm{C}$. After adding 2,4dinitrophenylhydrazine to the extraction, the mixture was allowed to stand for $3 \mathrm{hr}$ at room temperature in darkness. Finally, the hydrazone produced was dissolved in $2 \mathrm{ml}$ of absolute methanol. To separate and quantify the pyruvic acid in the keto acids, a 10- $\mu$ l aliquot of the solution was directly subjected to high-performance liquid chromatography (HPLC)

A Gaskuro Kogyo (Tokyo) liquid chromatograph (Model-570B) equipped with a sampling valve with a $20-\mu$ loop (Rheodyne Model 7120) was used. The chromatographic column $(4.0$ i-d. $\times 250 \mathrm{~mm})$ was of stainless steel and packed with Unicil Q30 (particle diameter $5 \mu \mathrm{m}$, Gaskuro Kogyo). The UV detector was set-at $254 \mathrm{~nm}$. A mobile phase [50 chloroform : 5 n-butanol : 5 acetic acid : 50 water (by volume)] was pumped through the column at a flow rate of $1 \mathrm{ml} \cdot \mathrm{min}^{-1}$. The chart speed was adjusted to $5 \mathrm{~mm} \cdot \mathrm{min}^{-1}$. Analytical-grade sodium pyruvate was purchased from Wako Pure Chemicals (Osaka, Japan). Chromatographic peak areas were calculated using a Shimazu Model-RIA electronic integrator (Shimazu Seisakusho, Kyoto, Japan).

The determination of GPT activity was performed according to the method of Jen et al. (4) or Romani (10); each 30-g sample of the edible portion was blended with $30 \mathrm{ml}$ of 0.1 MTris.HC1 (pH 7.4) at 4C. The slurry was centrifuged at $3000 \times \mathrm{g}$ and stored at $-20 \mathrm{C}$ for $20 \mathrm{~min}$, after which the supernatant was saturated with ammonium sulfate and allowed to stand overnight at $0 \mathrm{C}$. The precipitate was collected by centrifugation at $6000 \mathrm{x} \mathrm{g}$ and stored at - 20C until required. The precipitate was dissolved with $5 \mathrm{ml}$ of TrisHCl buffer and dialyzed with $0.01 \mathrm{M}$ Tris- $\mathrm{HCl}$ buffer for $40 \mathrm{hr}$ at $4 \mathrm{C}$. The components of the assay system were maintained at $\mathrm{pH}$ 7.4. The assay medium consisted of $80 \mu \mathrm{mol}$ Tris- $\mathrm{HCl}$ buffer ( $\mathrm{pH} 7.4), 10 \mathrm{~kg}$ pyridoxal-5-phosphate, $0.3 \mu \mathrm{mol} \mathrm{NADH}, 10$ $\mu \mathrm{mol}$ alanine, and $25 \mathrm{~kg}$ lactic acid dehydrogenase (Wako Pure. Chemicals). To the

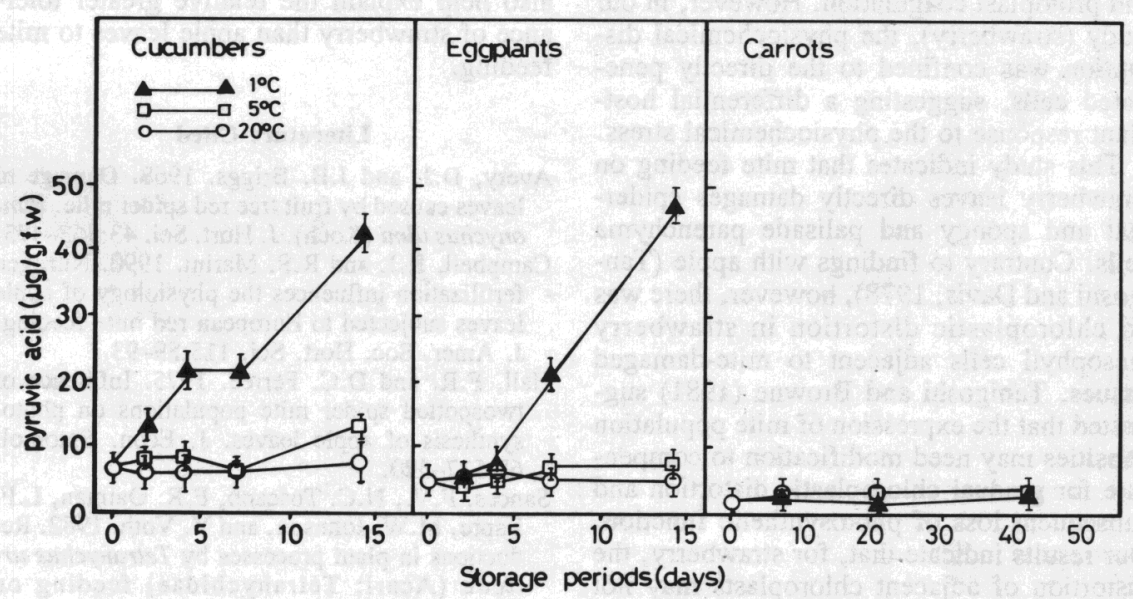

Fig. 1. Pyruvic acid content in cucumbers, eggplants, and carrots stored at 1,5 , or $20 \mathrm{C}$. Vertical 


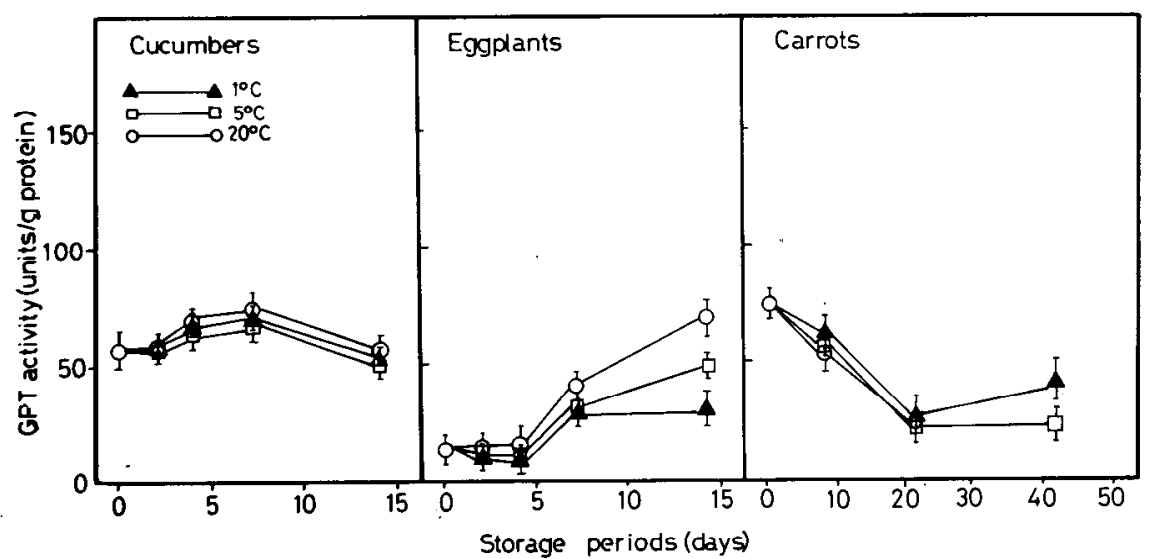

Fig. 2. GPT activity in cucumbers, eggplants, and carrots stored at 1,5 , or $20 \mathrm{C}$. Vertical bars indicate SE.

complete mixture, $0.1 \mathrm{ml}$ of enzyme was added, the changes in optical density at 340 $\mathrm{nm}$ were recorded, and, unless otherwise indicated, all assays were run at $25 \mathrm{C}$. The specific activity of GPT was expressed as units of activity per gram of protein.

Protein content was determined by the method of Lowry et al. (6) using a standard bovine serum albumin (Wako Pure Chemicals).

Pyruvic acid. $\alpha$-Keto acids (i.e., pyruvic acid, $\boldsymbol{\alpha}$-oxoglutaric acid, and oxaloacetic acid) play an important role in carbohydrate, lipid, and amino acid metabolism in biological samples. Pyruvic acid in cucumbers (chilling sensitive) increased during storage at $1 \mathrm{C}$, and, after 14 days, it had increased to more than 7 times the level at 20C (Fig. 1). At 5C, pyruvic acid content was similar to that at 20C; however, a slight increase was found at the end of storage. In eggplants (chilling sensitive), pyruvic acid increased during storage at $1 \mathrm{C}$ and, after 14 days, reached a level 9 times that measured oil the initial day of storage. However, when stored at SC, which usually causes chilling injury on cucumbers and eggplants, the increase in pyruvic acid was very low compared to the level in eggplants stored at $1 \mathrm{C}$. The reasons are unclear, but it might be that the materials used in this study were a little advanced in maturity and, therefore, more tolerant than younger fruit. The pyruvic acid content of carrots (not chilling sensitive) remained low at all temperatures tested.

From the above result, it is evident that pyruvic acid accumulation in chilling-sensitive crops is associated with the progression of chilling injury.

GPT activity. GPT is a very important enzyme involved in the metabolism between pyruvic acid and alanine in biological samples:

\section{Glutamate + pyruvate $\rightleftarrows \alpha$-oxoglutarate + alanine.}

In cucumbers, GPT activity increased slightly after 4 to 7 days of storage at all temperatures and then decreased, but there were no significant differences with respect to GPT activity between temperatures (Fig. 2). In eggplants, significant differences in GPT activity between storage at 1,5 , and $20 \mathrm{C}$ did not appear until the 4th day; subsequently, higher GPT activity than initial levels was observed even at $1 \mathrm{C}$ throughout the storage periods. GPT activity in carrots stored at 1 , 5 , or 20C decreased until 21 days of storage and then increased slightly by 42 days of storage at 1 or $5 \mathrm{C}$.

The reason why alanine accumulates in chilling-sensitive crops during cold storage is unclear, but the present study has demonstrated that pyruvic acid is rapidly accumulated in chilling-sensitive crops during cold storage (Fig. 1). Patterson et al. (9) suggested an increase of GPT activity because passion fruit leaves stored at $0 \mathrm{C}$ accumulated alanine, while glutamic acid was reduced. In this study, GPT activity was examined using cucumbers and eggplants, which are sensitive, and carrots, which are not sensitive to low temperature. However, GPT remained nearly unchanged in all three crops (Fig. 2). Thus, no influence of low temperature was observed on this enzyme. These facts suggested that the accumulated alanine may be produced by GPT from pyruvic acid that accumulated during cold storage. In addition, the cause of pyruvic acid accumulation in chillingsensitive crops during cold storage is unclear. Murata (7), in his tracer experiment using suc- cinic acid-1,4- ${ }^{14} \mathrm{C}$,reported that the pathway from oxaloacetic acid to citric acid in a banana peel was inhibited by cold storage. Also, it was reported that $\alpha$-keto acids ( $\alpha$-oxoglutaric acid and oxaloacetic acid), intermediates in the tricarboxylic acid (TCA) cycle, rapidly accumulated in the tissues of cucumb\&s (1), apples (2), bananas (7), and pepuers (8). which correlated with the progression of chilling injury. These facts suggest that disruption of the TCA cycle occurs during cold storage. Therefore, by measuring changes in TCA cycle and glycolysis intermediates and enzyme activity in chilling-sensitive crops, which are related to the biosynthesis of metabolites, the cause of pyruvic acid and alanine accumulation produced during cold storage may be elucidated.

\section{Literature Cited}

1. Hirose, T. 1987. Effect of intermittent warming on chilling injury and contents of $\alpha-\mid$ keto acid of cucumber fruits during cold storage. Sci. Rpt. Faculty Agr., Kobe Univ., Japan . 17:171-174

2. Hulme, A.C., W.H. Smith, and L.S.C. Wooltoron, 1964. Biochemical changes associated with the development of low temperature breakdown in apples. J. Sci. Food Agr. 15:303-307.

3. Isherwood, F.A. and D.H. Cruickshank. 19.54. Chromatographic separation and analysis of mixtures of pyruvic, oxaloacetic, and alpha-ketoglutaric acid. Nature (London) 173:121-122.

4. Jen, J.J. and C.S. Graham. 1975. Glutamic oxaloacetic transaminase activities during maturation. J. Food Sci. 40:934-936.

5. Kozukue, N., E. Kozukue, T. Hirose, and S. Mizuno. 1984. Accumulation of alanine in chilling-sensitive crops. HortScience 19:498-501.

6. Lowry, O.H., N.H. Rosebrough, A.L. Farr, and R.J. Randall. 1951. Protein measurement with the Folin phenol reagent. J. Biol. Chem. 193:265-275.

7. Murata, T. 1969. Physiological and biochemical studies of chilling injury in bananas. Physiol. Plant, 22:401-411.

8. Ogata, K.,N. Kozukue, and T. Murata. 1968. Quality changes and the mechanism of chilling injury in pepper fruits stored at low-temperature. J. Jpn. Soc. Hort. Sci. 37:249254.

9. Patterson, B.D., J.A. Pearson, L.A. Payne, and LB. Ferguson. 1981. Metabolic aspects of chilling resistance: Alanine accumulation and glutamate depiction in relation to chilling sensitivity in passionfruit species. Austral. J. Plant Physiol. 8:395-403.

10. Romani, R.J. 1962. Properties of transaminases in tissues of the pear. Plant Physiol. 37-523-526.

11. Wightman, F. and J.C. Forest. 1978. Properties of plant aminotransferases. Phytochemistry $17: 1455-1471$ 